\title{
Luminescent Hybrid Materials Based on Curcumin Derivatives Embedded in Palygorskite
}

\begin{abstract}
MONICA FLORENTINA RADULY, VALENTIN RADITOIU, ALINA RADITOIU, LUMINITA EUGENIA WAGNER*, VIORICA AMARIUTEI, CRISTIAN ANDI NICOLAE

Research and Development National Institute for Chemistry and Petrochemistry - ICECHIM, 202 Splaiul Independentei, 060021, Bucharest, Romania

The seven curcumin derivatives were deposited on palygorskite in order to obtain hybrid materials. The fluorescence emission spectra of the obtained materials show a decrease in fluorescence intensity relative to the respective dyes, due to the environments around the dyestuff molecules created in the host matrices. Absorption studies show the best adsorption on the inorganic matrix, for the compounds with the hydroxyl groups. Correlating fluorescence spectra of hybrid materials with the results for absorption spectra of the dyes adsorbtion on the surface of the clay lead to the conclusion that a high percentage of the adsorbed dye had the effect of fluorescence quenching. Thus, it was confirmed that the fluorescent properties of hybrid materials depend on the interactions established between the fluorescent dyestuff and the inorganic network.
\end{abstract}

Keywords : curcumin, chromogens, hybrid materials, fluorescent properties, palygorskite

Curcumin is a natural yellow coloured compound known for centuaries, extracted from the rhizome of Curcuma species, was used initially as a textile dye [1,2] and then used in diet as a spice or additives [3]. Curcumin applicability has been extended due to their antioxidant, anti-inflammatory and anticancer properties in biomedical domain [4-6]. In the recent years to develop and diversify curcumin derivatives with improved properties in terms of photostability and with increased efficiency of fluorescence emission, were made structural changes on the curcumine skeleton by alkylation, acylation or as metal-complexes [7]. Several curcumin derivatives have been incorporated into inorganic networks (porous materials, natural or synthetic zeolites), thus obtaining hybrid materials with improved photochemical properties for non-conventional applications [8-11].

In many studies on the adsorption of dyes on clays, palygorskite (or attapulgite) was used as an efficient adsorbent [12-14]. Palygorskite (PAL) clay is a natural white-gray, with high hydrophilic properties, abundant in nature and relatively inexpensive. Depending on the area from which the palygorskite comes, it may contain iron, calcium, potassium and sodium ions in various proportions, [ Mg ( $\left.\left.\mathrm{Al}_{0.5-1} \mathrm{Fe}_{0.0 .5}\right)\right] \mathrm{Si}_{4} \mathrm{O}_{10}(\mathrm{OH}) \cdot 4 \mathrm{H}_{2} \mathrm{O}$ (chemical composition: $\mathrm{SiO}_{2}$ 2.50-68\%; $\mathrm{Al}_{2} \mathrm{O}_{3}$ 9-12\%; $\mathrm{MgO}^{2} \mathrm{3}-12 \% ; \mathrm{Fe}_{3} \mathrm{O}_{3}$ 3-5\%). Due to its structure containing open channels, the palygorskite falls within the category of porous materials, with a surface area that varies between $75-400 \mathrm{~m}^{2} / \mathrm{g}[15,16]$. Due to it lamellar structure, the palygorskite has remarkable properties for chemical stability and durability when exposed to various external factors. These properties have made it to be used in studies aimed at obtaining luminescent nanocomposites [17] and in biological applications [18].
Based on these considerations, this study is intended to provide data on obtaining hybrid materials with luminescent properties by depositing of the curcumin derivatives on an inorganic matrix. The curcumin derivatives were previously synthesized in the microwave field, purified and characterized [19].

\section{Experimental part}

The present paper illustrates experimental data regarding synthesis and characterization of seven new organic-inorganic hybrids obtained by curcumin derivatives (fig.1) depositing on surface of palygorskite inorganic matrix.

All of the chemicals used were of laboratory reagent grade and were obtained from Merck (Germany) and Aldrich (USA). Methanol (MeOH), hexadecyltrimethylammonium bromide (CTAB), and hydrochloric acid (0.1 $\mathrm{N})$ were used as they were received without further purification. The Palygorskite (PAL) clay used in this study was obtained from SERVA (Germany).

The curcumin derivatives (ccl-cc7) were deposited on PAL previously modified with hydrochloric acid and hexadecyltrimethylammonium bromide (CTAB) $[13,18]$.

\section{Surface treatment of palygorskite}

PALs were activated in a $5 \mathrm{M} \mathrm{HCl}$ solution at $100^{\circ} \mathrm{C}$ for $4 \mathrm{~h}$, and then washed with water until neutral $\mathrm{pH}$. Afterwards the crude product was dried at $120^{\circ} \mathrm{C}$ for $5 \mathrm{~h}$ in order to getactivated PALS. CTAB $(0.01 \mathrm{~mol})$ was dissolved in water $(300 \mathrm{~mL})$ at $p \mathrm{H}=3$ and $60^{\circ} \mathrm{C}$, and after complete dissolution it was added Palygorskite $(10 \mathrm{~g})$ and then stirred at $60^{\circ} \mathrm{C}$ for $12 \mathrm{~h}$. The dispersion was filtered, washed with water to $\mathrm{pH}=7$ and dried at $120^{\circ} \mathrm{C}$ for $24 \mathrm{~h}$.<smiles>[R4]c1cc(/C=C/C(=O)CC(=O)/C=C/c2cc([R3])c([R4])c([R4])c2[R])c([R4])c([R])c1[R4]</smiles>

* email: luminitawagner@yahoo.com

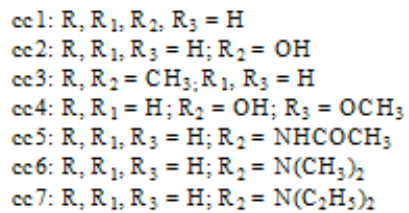

Fig.1 Structural formula of curcumin derivatives 
General method of depositing dyes on modified palygorskite

The modified palygorskite was used as the inorganic matrix on which the curcumin derivatives were deposited, thus obtaining hybrid materials. To this purpose, modified palygorskite (PAL-CTAB) $(0.5 \mathrm{~g})$ was suspended in alcoholic solution of $0.004 \%$ curcumin derivative (cc1-cc7) and refluxed for 3 hours. The dispersion was filtered and dried at $70^{\circ} \mathrm{C}$ for $1 \mathrm{~h}$. The obtained hybrid materials were characterized by IR, TGA, fluorescence spectra and porosimetry.

\section{Adsorption experiments}

In order to evaluate the adsorption of curcumin derivatives on the surface of the inorganic matrix, experiments were conducted with the modified palygorskite, which was suspended in dye alcoholic solution by the method presented in the literature [14]. PAL-CTAB $(0.2 \mathrm{~g})$ was suspended in $100 \mathrm{~mL}$ dye alcoholic solution $100 \mathrm{mg} / \mathrm{L}$ for one hour at $30^{\circ} \mathrm{C}$. The dispersion was filtered and dried at $70^{\circ} \mathrm{C}$ for $1 \mathrm{~h}$, and the dye concentration was measured spectrophotometrically at $\lambda$ of $391 \mathrm{~nm}$, $416 \mathrm{~nm}, 397 \mathrm{~nm}, 422 \mathrm{~nm}, 414 \mathrm{~nm}, 416 \mathrm{~nm}, 499 \mathrm{~nm}$ for compound $\mathrm{Cc} 1$ - $\mathrm{Cc} 7$. Using the equation (1), the sorption degree of the dye on the inorganic matrix was calculated.

$$
\text { Sorption degree }(\%)=\left(C_{0}-C_{1}\right) \cdot 100 / C_{0}
$$

where $C_{0}$ and $C$ represent the initial and final concentrations $(\mathrm{mg} / \mathrm{L})$, respectively.

\section{Measurements}

IR spectra of all the studied compounds were recorded on a J asco FTIR 6300 spectrometer equipped with a Specac ATR Golden Gate (KRS5 lens), in the $400-4000 \mathrm{~cm}^{-1}$ range (32 accumulations at a resolution of $4 \mathrm{~cm}^{-1}$ ).

Total color differences in CIELAB system, using a 10 degrees standard observer and illuminant D65, diffuse reflectance spectra of powders and transmission spectra of solutions and films were measured with a JASCO V570 UV-Vis-NIR spectrophotometer equipped with a JASCO ILN $-472(150 \mathrm{~mm}$ ) integrating sphere, using spectralon as reference.

Fluorescence spectra were recorded with a JASCO FP 6500 spectrofluorimeter, at $25^{\circ} \mathrm{C}$, using the device for solid samples at an excitation wavelength of $435 \mathrm{~nm}$.

In order to investigate the thermal stability of the hybrid composites, TGA was performed using a Q5000IR (TA Instruments) thermogravimetric analyzer. The samples were heated up to $800^{\circ} \mathrm{C}$ from the ambient temperature at a heating rate of $10^{\circ} \mathrm{C} / \mathrm{min}$ under $50 \mathrm{~mL} / \mathrm{min}$ Nitrogen (99.999\%) atmosphere.

Surface area and relative measurements of raw clay and hybrid materials were performed using Nova 2200e Quantachrome.

\section{Results and discussions}

In this study seven curcumin compounds derivatives of acetylacetone (cc1-cc7) previously synthesized [19] in the microwave field were deposited on attapulgite (palygorskite) through the adsorption process, obtaining hybrid organic-inorganic materials.

By the deposition of dyes on the palygorskite, organicinorganic hybrid materials were obtained, characterized by FTIR spectra, thermogravimetric analysis, specific surface area measurement and fluorescence spectra.

The analysis of IR spectra (fig.2) recorded for natural and modified palygorskite after acid treatment shows characteristic peaks according to literature data [13], a band between $3650^{-1}-3200 \mathrm{~cm}^{-1}$ representing the stretching vibration of hydrogen bonded hydroxyl groups. The 1654 $\mathrm{cm}^{-1}$ peak was attributable to $\mathrm{H}-\mathrm{O}-\mathrm{H}$ bending vibrations, corresponded adsorbed water in the inorganic network. The $1422 \mathrm{~cm}^{-1}$ and $1194 \mathrm{~cm}^{-1}$ peaks indicate the bonding region of aluminum, which disappears after acid treatment when dislodged in the form of salts. After treatment with hydrochloric acid, the structure of the clay undergoes changes evidenced by the appearance of the peak at 793 $\mathrm{cm}^{-1}$, attributable to Si-O bending vibration, and peak displacement of the most intense bands in the spectra from 976 to $1058 \mathrm{~cm}^{-1}$, attributed to Si-O-Si stretching vibrations. After modifying the palygorskite surface with CTAB, the FTIR spectrum shows the absorption bands around at $2929 \mathrm{~cm}^{-1}$ and $2852 \mathrm{~cm}^{-1}$, attributed to the oscillation of stretching vibration of methylene group, confirming thus the success of the organic modification of the clay.

The IR spectra of hybrid materials obtained after the dye was deposited on the clay surface showed the displaced peaks characteristic of $\alpha, \beta$-unsaturated compounds, respectively $1740 \mathrm{~cm}^{-1}$ due to hydrogen bonds and $1695 \mathrm{~cm}^{-1}$ corresponds to the stretching vibration of $\mathrm{C}=0$. The disappearance of peaks at $2929 \mathrm{~cm}^{-1}$ and 2852 $\mathrm{cm}^{-1}$ characteristic of CTAB leads to the conclusion that during the adsorption process, the surfactant passes into the solution and promotes the process of depositing the dye on the clay surface.

The color parameters (lightness ( $\left.\mathrm{L}^{*}\right)$, red-green (a*) and yellow-blue (b*) color component), calculated from the spectralon (CCO) and the color differences to the clay, modified with CTAB shows that PAL $\mathbf{4}$ has the highest ÄE value in the series.

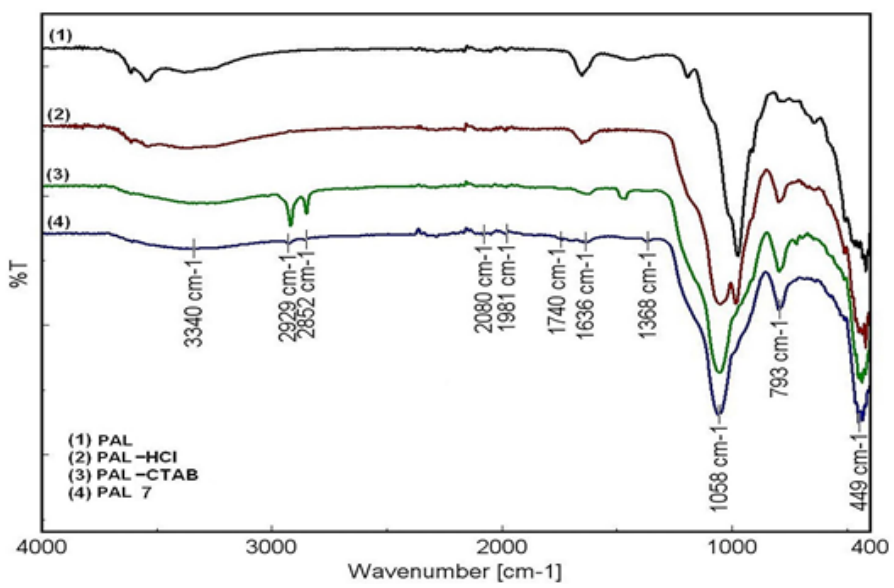

Fig.2. IR spectra of commercial clay, treated clay powders and the hybrid composites

The obtained results reveal that the lightness of the samples decreases with the increase of the volume of the substitution groups in the aromatic rings, and the color of the sample become yellowish ( $\Delta \mathrm{b}$ increases). The color characteristics of the hybrids are also influenced by the conjugations of organic derivatives with the hydroxyl groups on the surface of the clay, so in the compounds PAL2, PAL4 and PAL5 where hydrogen bonds are present, the colors are lighter ( $\Delta$ C increases), while for the PAL 6 and PAL7 where polar bonds occur between organic and inorganic compounds, the color has become dull and dark.

Curcumin and its derivatives deposited on the porous material have maximum adsorption in the UV-Vis spectrum around $400-441 \mathrm{~nm}$ displaced by $9-64 \mathrm{~nm}$ over the maxima obtained in the solution. Thus another important factor is 
Table 1

COLOR PARAMETERS AND DIFFERENCES IN THE CIELAB SYSTEM

\begin{tabular}{|c|c|c|c|c|c|c|c|c|c|}
\hline \multirow{2}{*}{ Sample } & \multicolumn{9}{|c|}{ Color parameters and differences } \\
\hline & $\mathrm{L}^{*}$ & $a^{8}$ & $\mathrm{~b}^{*}$ & $\Delta \mathrm{L}^{*}$ & $\Delta \mathrm{a}^{8}$ & $\Delta \mathrm{b}^{*}$ & $\Delta \mathrm{E}_{\mathrm{ab}}{ }^{*}$ & $\Delta \mathrm{C}^{*}$ & $\Delta \mathrm{H}^{*}$ \\
\hline $\mathrm{CCO}$ & 93.21 & -0.56 & -0.57 & - & - & - & - & - & - \\
\hline $\begin{array}{l}\text { PAL- } \\
\text { CTAB }\end{array}$ & 92.10 & 0.42 & 2.27 & -1.11 & 0.98 & 2.84 & 3.20 & 1.51 & 2.60 \\
\hline PAL 1 & 90.51 & -0.47 & 6.51 & -2.70 & 0.09 & 7.09 & 7.58 & 5.73 & 4.17 \\
\hline PAL 2 & 89.70 & 0.49 & 8.21 & -3.51 & 1.05 & 8.78 & 9.51 & 7.42 & 4.80 \\
\hline PAL 3 & 89.77 & -0.42 & 6.13 & -3.44 & 0.14 & 6.70 & 7.53 & 5.35 & 4.04 \\
\hline PAL 4 & 86.83 & 1.37 & 9.28 & -6.38 & 1.93 & 9.85 & 11.89 & 8.58 & 5.21 \\
\hline PAL 5 & 89.73 & 0.25 & 7.84 & -3.48 & 0.81 & 8.41 & 9.13 & 7.04 & 4.67 \\
\hline PAL 6 & 87.58 & 2.42 & 4.97 & -5.63 & 2.98 & 5.54 & 8.44 & 4.73 & 4.15 \\
\hline PAL 7 & 87.02 & 2.67 & 2.25 & -6.19 & 3.23 & 2.82 & 7.53 & 2.69 & 3.34 \\
\hline
\end{tabular}
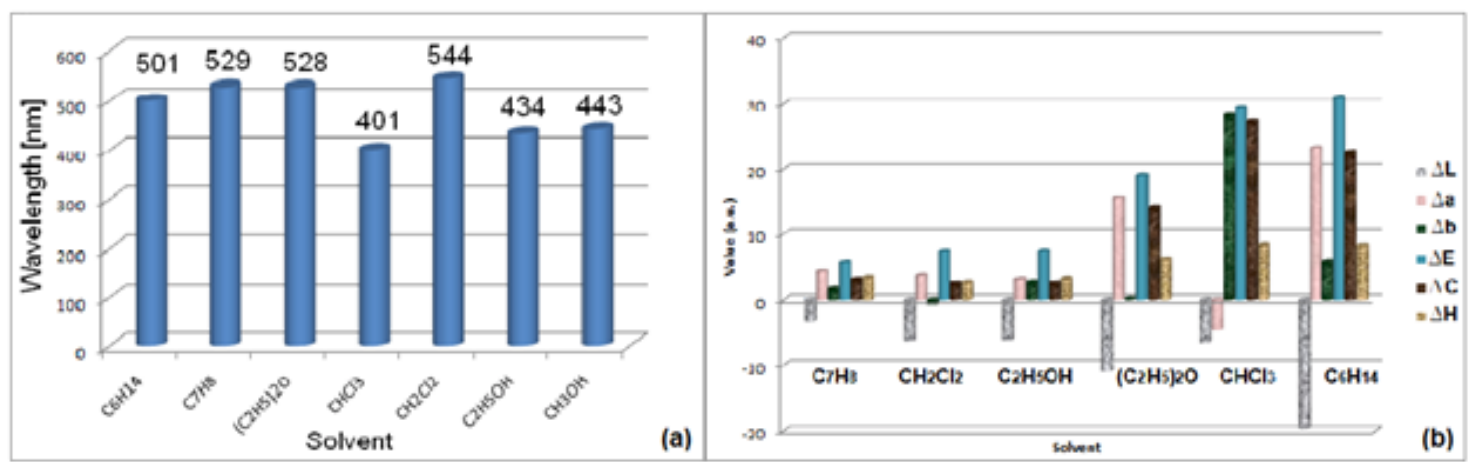

Fig. 3. Absorption maxima (a) and colour differences (b) of hybrid compound PAL7 obtained from different solvents

the solvent from which the dye is deposited on the porous material, because a small part of it remains in the pores and plays an important role in conjugating the organic compound to the matrix anorganic. In non-polar solvents the adsorption maxima were found at values between 501-544 nm for PAL 7 figure 3 (a), the batochromic displacement is explained by the conjugations between the amine groups of the curcumin derivative and the hydroxy groups on the clay surface. The PAL 7 derivative retains its solvatochromic properties, thus obtaining a pale pink hybrid from the methylene dichloride solution, from the diethylether solution, the hybrid obtained is pink, while the chloroform solution results in a yellow compound, and from the hexane solution the color of the hybrid is orange. Thus, hybrids with directed color properties can be obtained, as shown in figure 3 (b), where it can be seen that the hybrid obtained by depositing the curcumin derivative in hexane has the total color difference $(\Delta \mathrm{E})$ and the lightness $(\Delta \mathrm{L})$ with the highest values in the series of solvents and is an indication of the fluorescence intensity.

Thermal analysis data for the commercial powder clay, palygorskite treated with CTAB and palygorskite after adsorption of the dye were presented in table 2. All TG curves show a first stage at a temperature around $110^{\circ} \mathrm{C}$, due to the evaporation of the adsorption water, the mass loss was of $6.9 \%$ for raw clay and between $4.3-5.4 \%$ for palygorskite after adsorption of the dye.

The second stage takes place at around $200^{\circ} \mathrm{C}$, corresponding to the hygroscopic water and zeolitic water [13]. The PAL-CTAB curve shows a significant weight loss (31\%) in the range of $200-300^{\circ} \mathrm{C}$, attributed to CTAB degradation. In the meanwhile, for the palygorskite with dye cc1-cc7 the curve shows a mass loss between 2.0$4.4 \%$ in the $250-350^{\circ} \mathrm{C}$ range, attributed to the degradation of the dye deposited on the inorganic matrix. The most important weight loss in this step is recorded in the case of
PAL 6, followed by PAL 3 and PAL 4 and it is of about 4.4, respectively $4.3 \%$. Over $300^{\circ} \mathrm{C}$, mass loss corresponds to the loss of coordinated water and structural hydroxyl water in palygorskite. As shown in table 2, due to the thermal decomposition in an inert atmosphere, the residue for all hybrids is high and it is formed of silica from the inorganic matrices and carbonaceous char of organic moieties.

The specific surface area $\left(S_{B \in T}\right)$ and the adsorption average pore size were determined using the multipoint BET (Brunauere-Emmette-Teller) method. The total pore volume $\left(\mathrm{V}_{\text {tot }}\right)$ and pore size were determined by using the BJ H (Barrette-J oynere-Halenda) method. Prior to each measurement the samples were degassed at $423 \mathrm{~K}$ for 4 h. Adsorption and desorption experiments using $\mathrm{N}_{2}$ were carried out at $77 \mathrm{~K}$. The isotherms recorded were classified as type II with a $\mathrm{H} 3$ hysteresis, in accordance with the IUPAC classification according to the literature [20]. From the data presented in table 3 that shows the values for the specific surface area, it can be observed that the surface areas of the samples increase in the following order: PAL $5<$ PAL $1<$ PAL $2<$ PAL $6<$ PAL $7<$ PAL $3<$ PAL 4 . This trend can be understood in terms of the size and orientation of the auxocromatic groups of organic compounds on the silica matrix.

Pore diameter was, on average, greater than the $3 \mathrm{~nm}$ characteristic of mesoporous materials. Thus, it can be seen that natural clay has a specific surface area of 117 $\mathrm{m}^{2} / \mathrm{g}$ and, depending on the volume and the number of grafted groups on the aromatic rings, the surface increases up to $204.5 \mathrm{~m}^{2} / \mathrm{g}$ for the curcumin modified palygorskite.

Hybrid materials obtained by deposition of the dye on the surface of the clay proved fluorescence properties (fig.4). The samples were measured in the $350-700 \mathrm{~nm}$ range, at the same wavelength $(435 \mathrm{~nm})$, indicating a decrease in the fluorescence intensity as compared to the curcumin derivatives in the alcoholic solution (table 4). 
Table 2

THERMOGRAVIMETRIC ANALYSIS OF FLUORESCENT POWDERS

\begin{tabular}{|c|c|c|c|c|c|c|c|c|c|c|c|c|c|c|}
\hline \multirow[t]{2}{*}{ Sample } & \multirow{2}{*}{$\begin{array}{l}\text { RT- } \\
110 \\
{ }^{\circ} \mathrm{C} \\
\begin{array}{l}\text { Wt. } \\
\text { loss }\end{array} \\
\end{array}$} & \multicolumn{3}{|c|}{$110^{\circ} \mathrm{C}-\mathrm{T}_{1}$} & \multicolumn{3}{|c|}{$T_{1}-T_{2}$} & \multicolumn{3}{|c|}{$T_{2}-T_{3}$} & \multicolumn{3}{|c|}{$T_{3}-T_{4}$} & $\begin{array}{c}\text { Residue } \\
800\end{array}$ \\
\hline & & $\begin{array}{l}\text { Wt. } \\
\text { loss }\end{array}$ & $\mathbf{T}_{\max }$ & $T_{1}$ & $\begin{array}{l}\text { Wt. } \\
\text { loss }\end{array}$ & $T_{\max }$ & $T_{2}$ & Wt. loss & $T_{\max }$ & $T_{3}$ & Wt. loss & $T_{\max }$ & $T_{4}$ & $\begin{array}{l}800 \\
{ }^{\circ} \mathrm{C} \\
\end{array}$ \\
\hline & $\%$ & $\%$ & ${ }^{\circ} \mathrm{C}$ & ${ }^{\circ} \mathrm{C}$ & $\%$ & ${ }^{\circ} \mathrm{C}$ & ${ }^{\circ} \mathrm{C}$ & $\%$ & ${ }^{\circ} \mathrm{C}$ & ${ }^{\circ} \mathrm{C}$ & $\%$ & ${ }^{\circ} \mathrm{C}$ & ${ }^{\circ} \mathrm{C}$ & $\%$ \\
\hline PAL & 6.9 & 2.8 & 168.4 & 265.6 & 1.8 & 365.8 & 398.3 & 2.9 & 445.5 & 541.1 & 3.4 & 642.4 & 800 & 82.2 \\
\hline $\begin{array}{l}\text { PAL - } \\
\mathrm{HCl}\end{array}$ & 6.9 & 1.1 & 152.4 & 205.4 & 5.2 & 357.6 & - & - & - & - & - & - & 800 & 86.9 \\
\hline $\begin{array}{l}\text { PAL - } \\
\text { CTAB }\end{array}$ & 2.5 & 31.4 & 234.3 & 335.3 & 1.8 & 377.5 & 513.5 & - & - & - & 1.3 & 552.1 & 800 & 63.1 \\
\hline PAL 1 & 5.1 & 0.6 & 139.2 & 183.4 & 2.0 & 272.5 & 324.9 & 2.2 & 392.8 & 475.8 & 2.2 & 542.9 & 800 & 88.0 \\
\hline PAL 2 & 5.3 & 0.6 & 137.9 & 182.1 & 2.0 & 275.6 & 321.4 & 2.1 & 390.8 & 468.6 & 2.3 & 541.2 & 800 & 87.7 \\
\hline PAL 3 & 5.3 & 1.2 & 151.1 & 205.6 & 4.3 & 358.9 & 508.3 & - & - & - & 1.9 & 538.6 & 800 & 87.3 \\
\hline PAL 4 & 5.5 & 1.1 & 144.4 & 198.3 & 4.3 & 353.5 & 508.1 & - & - & - & 1.8 & 544.3 & 800 & 87.4 \\
\hline PAL 5 & 4.3 & 0.6 & 133.6 & 178.7 & 2.5 & 277.6 & 330.5 & 2.0 & 378.9 & 485.6 & 2.1 & 557.1 & 800 & 88.5 \\
\hline PAL 6 & 5.3 & 1.2 & 144.7 & 201.8 & 4.4 & 353.0 & 511.9 & - & - & - & 1.8 & 542.2 & 800 & 87.3 \\
\hline PAL 7 & 4.9 & 0.6 & 136.3 & 179.1 & 2.3 & 276.4 & 333.4 & 2.4 & 391.5 & 509.4 & 2.0 & 545.2 & 800 & 87.8 \\
\hline
\end{tabular}

\begin{tabular}{|c|c|c|c|}
\hline Sample & $\begin{array}{c}\text { Surface area } \\
(\text { method BET) } \\
{\left[\mathbf{m}^{2} / \mathbf{g}\right]}\end{array}$ & $\begin{array}{c}\text { Total Pore } \\
\text { Volume } \\
\text { (method BJH) } \\
\text { [cm } / \mathbf{g}]\end{array}$ & $\begin{array}{c}\text { Diameter pore } \\
\text { (method BJH) } \\
\text { [nm] }\end{array}$ \\
\hline PAL & 117.0 & 0.327 & 3.85 \\
\hline PAL 1 & 190.5 & 0.627 & 3.49 \\
\hline PAL 2 & 190.7 & 0.615 & 3.19 \\
\hline PAL 3 & 197.3 & 0.592 & 3.24 \\
\hline PAL 4 & 204.5 & 0.675 & 4.24 \\
\hline PAL 5 & 190.2 & 0.497 & 3.48 \\
\hline PAL 6 & 193.5 & 0.383 & 3.17 \\
\hline PAL 7 & 196.4 & 0.657 & 5.18 \\
\hline
\end{tabular}

Table 3

BET SPECIFIC SURFACE, AREA MICROPORE,VOLUME AND DIAMETER PORE OF PAL, PAL 1 -PAL 7

\begin{tabular}{|c|c|c|c|c|}
\hline $\begin{array}{c}\text { Hybrid compounds } \\
\text { (dye in alcoholic solution) }\end{array}$ & $\begin{array}{l}\lambda_{a b s} \\
{[\mathrm{~nm}]}\end{array}$ & $\begin{array}{c}\lambda_{\max } \\
{[\mathrm{nm}]}\end{array}$ & $\begin{array}{l}\lambda \mathrm{em} \\
{[\mathrm{nm}]}\end{array}$ & $\begin{array}{c}\text { Stokes Shift } \\
{[\mathrm{nm}]}\end{array}$ \\
\hline PAL1 (cc1) & $413(389)$ & \multirow{7}{*}{435} & $485(495)$ & $72(106)$ \\
\hline PAI $2(\operatorname{cc} 2)$ & $435(415)$ & & $525(530)$ & $90(115)$ \\
\hline PAL $3(\operatorname{cc} 3)$ & $422(400)$ & & $490(505)$ & $68(105)$ \\
\hline PAL 4 (cc4) & $441(425)$ & & $525(545)$ & $84(120)$ \\
\hline PAL $5(\operatorname{cc} 5)$ & $425(413)$ & & $525(530)$ & $100(117)$ \\
\hline PAL 6 (cc6) & $404(413)$ & & $534(545)$ & $130(132)$ \\
\hline PAL $7(\mathrm{cc} 7)$ & $434(498)$ & & $530(545)$ & $96(47)$ \\
\hline
\end{tabular}

Table 4

ADSORPTION AND FLUORESCENCE MAXIMA OF HYBRID MATERIALS
Analyzing the fluorescence spectra of the samples, it was observed that the PAL 4, PAL 5 and PAL 7 compounds had the same emission peak at $525 \mathrm{~nm}$ but at different intensities. Changing the wavelength of the fluorescence emission spectra varies between $5-20 \mathrm{~nm}$ is due to the lack of solventand its interactions, leading to the reduction of the polar tautomer structures of the dye molecules in the interaction with the illuminated radiation. There are also studies [21] in the literature that the curcumin in polar solvent is predominantly found in enolic form, which can explain the formation of intramolecular and intermolecular hydrogen bonding with the hydroxylic groups on the clay surface. The interactions between the auxochromes groups grafted on aromatic rings and the hydroxy groups on the inorganic matrix, all these factors contribute significantly to the reduction of the fluorescence intensity of the hybrid materials. Thus, result that the host matrix influence the $\pi-\pi$ / excited state by reducing the transition energy.

The dye adsorption ratio was calculated by difference from the dye concentrations in solutions before and after adsorption by measuring the absorption of the initial and final dye solutions of the adsorption process (fig.5). Compound cc2 was best adsorbed and this result might be attributed to the electrostatic interactions and hydrogen bonds between adsorbent and the hydroxyl groups of the dye. By analyzing the spectra, it followed that the fluorescence intensity of this composite material decreased greatly, probably due to the percentage of adsorbed dye. This phenomenon is compared to the tendency of aggregation in solutions that lead to quenching fluorescence. The weaker absorption of compounds cc1 and cc4 on clay surface can be explained by the absence of polar groups in the first compound and by the increased size of the molecular structure of the other. 


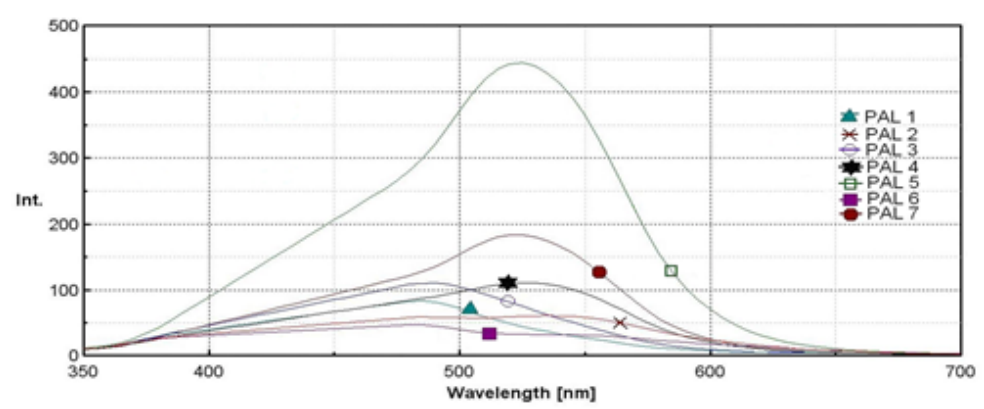

Fig.4. Fluorescence spectra of the hybrid composites (PAL1-7)

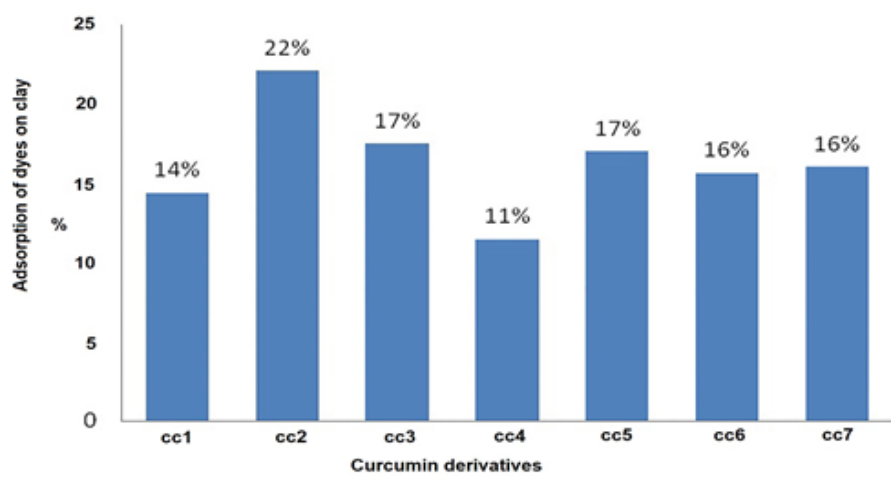

Fig.5. Sorption rate (\%) of curcumin derivatives (ccl-cc7) on the surface of modified palygorskite

\section{Conclusions}

By doping the attapulgite with the synthesized curcumine dyes (cc1-cc7), seven new hybrid materials were obtained. Hydrogen bonds with the inorganic matrix and the percentage of fluorophore adsorbed on the clay surface strongly influence the characteristics of the fluorescence emission. The inorganic matrix is part of the class of transporters, providing a stable environment for curcumin derivatives, while preserving their fluorescent properties, which results in organic-inorganic hybrid materials with potential applications in optical sensors and luminescent materials.

Funding: This work was supported by the National Authority for Scientific Research and Innovation [Project PN 16.31.03.03. and PN 16.22.04.02.].

\section{References}

1. HAN S., YANG Y., Dyes Pigm., 64(2) , 2005, p. 157-161

2. KULKARNI S.J., MASKE K.N., BUDRE M.P., MAHAJAN R.P., Int. J. Pharm. Pharm. Tech., 1(2), 2012, p.81-84
3. ROHMAN A., Int. Food Res. J., 19(1), 2012, p.19-27

4. NASRI H., SAHINFARD N., RAFIEIAN M., RAFIEIAN S., SHIRZAD M., RAFIEIAN-KOPAEI M., J HerbMed Pharmacol., 3(1), 2014, p.5-8

5.BASNET P., SKALKO-BASNET N., Molecules, 2011, 16, p.4567-4598 6. NOORAFSHAN A., ASHKANI-ESFAHANI S., Curr. Pharm. Des., 19, 2013, p.2032-2046

7. PRIYADARSINI K. I., Molecules, 19, 2014, p.20091-20112

8. BOLLU V. S., BRUI A. K., MONDAL S. K., PRASHAR S., FAJARDO M., BRIONES D., RODRIGUEZ-DIEGUEZ A., PATRA C. R., GOMEZ-RUIZS., Mater. Sci. Eng.C, 63(1), 2016, p. 393-410

9. HEIDARI A., J Nanotech Mater Sci., 4(2), p.1-5

10. ZHENG M., LIU S., GUAN X., XIE Z., Appl. Mater. Interfaces, 2015, 7 (40), p. 22181-22187

11. ONIDA B., BONELLI B., LUCCO-BORLERA M., FLORA L., OTERA AREÁN C., GARRONE E., Stud. Surf. Sci. Catal., 135, 2001, p. 364 12. CHEN X., SONG X., SUN Y., Int. J. Polym. Sci., 2016, http://dx.doi.org/ $10.1155 / 2016 / 2081734$

13. WANG W. B., WANG A. Q., Carbohydr. Polym., 82(1), 2010, p. 83-91 14. XUE A., ZHOU S., ZHAO Y., LU X., HAN P., J. Hazard. Mater. 194, 2011, p.7-14.

15. BARRER R.M., MACKENZIE N., J. Phys. Chem., 58, 1954, p.560-568. 16. TANG Y., ZHANG H., LIU X., CAI D., FENG H., MIAO C., WANG X., WU Z., YU Z., Water Res., 45, 2011, p.2855 - 2862.

17. MA Y., WANG H., LIU W., WANG Q., XU J., TANG Y., J. Phys. Chem. B, 113 (43), 2009, p. 14139-14145.

18. XU J., SUN Z., JIA L., LI B., ZHAO L., LIU X., MA Y., TIAN H., WANG Q., LIU W., TANG Y., Dalton Trans., 40, 2011, p.12909-12916. 19. RADULY, M. F., RADITOIU, V., RADITOIU, A., WAGNER, L. E., AMARIUTEI, V., AILIESEI-DARVARU, G., Facile synthesis of Curcumin and curcuminoid-like derivatives at microwaves, Rev. Chim.(Bucharest), 69, no. 6, 2018,( in press)

20. L. BOUDRICHE, R. CALVET, B. HAMDI, H. BALARD, Colloids Surf. A Physicochem. Eng. Asp., 392(1), 2011, p. 45-54.

21. CHIGNELL C. F., BILSKI P., RESZKA K.J ., MOTTEN A. G., SIK R. H., DAHL T. A., J. Photochem. Photobiol., 59(3), 1994, p. 295-302.

Manuscript received: 4.09 .2017 